\title{
ANALYTICAL AND NUMERICAL EVALUATION OF LIMIT STATES OF MSE WALL STRUCTURE
}

\author{
Marián DRUSA ${ }^{1, *}$, Jozef VLČEK ${ }^{1}$, Martina HOLIČKOVÁ ${ }^{1}$, Ladislav KAIS ${ }^{1}$ \\ ${ }^{1}$ Department of Geotechnics, Faculty of Civil Engineering, University of Žilina, Univerzitná 8215/1, \\ 01026 Žilina, Slovakia. \\ corresponding author: marian.drusa@fstav.uniza.sk.
}

\begin{abstract}
Simplification of the design of Mechanically Stabilized Earth wall structures (MSE wall or MSEW) is now an important factor that helps us not only to save a time and costs, but also to achieve the desired results more reliably. It is quite common way in practice, that the designer of a section of motorway or railway line gives order for design to a supplier of geosynthetics materials. However, supplier company has experience and skills, but a general designer does not review the safety level of design and its efficiency, and is simply incorporating into the overall design of the construction project. Actually, large number of analytical computational methods for analysis and design of MSE walls or similar structures are known. The problem of these analytical methods is the verification of deformations and global stability of structure. The article aims to clarify two methods of calculating the internal stability of MSE wall and their comparison with FEM numerical model. Comparison of design approaches allows us to draft an effective retaining wall and tells us about the appropriateness of using a reinforcing element.
\end{abstract}

\author{
Keywords: \\ Mechanically Stabilized Earth \\ (MSE); \\ Analytical design; \\ FEM model; \\ Internal stability; \\ Soil reinforcement.
}

\section{Introduction}

Reinforced soil structures (RSS) or mechanically stabilized earth structures (MSE) are widely used in transport construction now. These structures take advantage of reinforcement, which is defined as soil-inclusion stress transfer occurring continuously along the inclusion or reinforced element. Inclusion (reinforced element) is a generic term that encompasses all man-made elements incorporated in the soil to improve its behaviour, e.g. steel strips, geotextile, steel or polymeric grids geogrids (GGR), nails and steel tendons between anchorage elements. Mechanically Stabilized Earth Wall (MSE wall or MSEW) is a generic term that includes reinforced soil (a term used when multiple layers of inclusions act as reinforcement in soils placed as fill), [1].

Reinforced soil structures since its introduction are designed and evaluated by the analytical methods of calculation, which in itself must include a certain amount of simplification and generalization. These methods are particularly effective for the geometry design, ultimate limit state evaluation, and the determination of the maximum tensile strength of the reinforcing elements and the necessary anchoring length to embankment fill. In contrast, numerical modelling allows a better view of the behaviour of structures in the phase of construction and operation as analytical methods, especially when assessing the serviceability limit state structures - the level of maximum deflection. In addition to performing auxiliary tasks in assessing the serviceability limit state design, numerical modelling is an appropriate tool for complex design and assessment of reinforced retaining structures by geosynthetics.

\section{Internal stability checks of MSE wall structure}

In order to meet internal stability condition, all reinforcing elements must transfer all the tensile forces inside the structure through the friction and stiffness. In assessing internal stability, it is appropriate to focus on the local stability of the individual layers of elements. In this case, three types of failures must be examined: 
a) the stability of individual components,

b) resistance to displacement of the upper layers of the structure,

c) and stability of wedges of soil reinforced block. $[2,3]:$

The article aims to compare the assessment of internal stability structure through two methods,

- Tieback Wedge Method,

- and Coherent Gravity Method.

\subsection{Tieback Wedge Method}

For the internal stability check it is necessary to calculate the tensile force $T_{i}$ in level of the reinforcement of the $\mathrm{i}$-th layer. It can be expressed as the sum of forces acting on the structure:

$T_{i}=T_{F i}+T_{v i}+T_{H i} \quad$ for non-cohesive backfill,

$T_{i}=T_{F i}+T_{v i}+T_{H i}-T_{c i}$ for cohesive backfill,

where: $T_{F i}$ - is the resultant force of active load $q$ and self-weight inside the fill calculated by Eq. (3),

$T_{V i}$ - is vertical load from local surcharge,

$T_{H i}$ - is horizontal force indicated from local surcharge,

$T_{c i}$ - is a passive force indicated by cohesion of backfill.

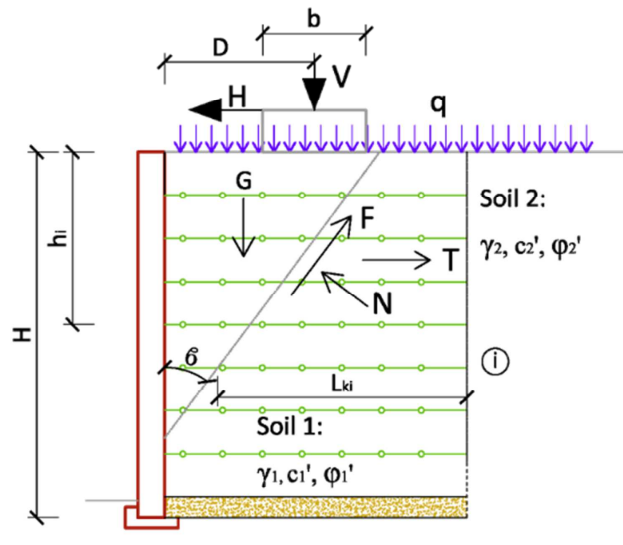

a)

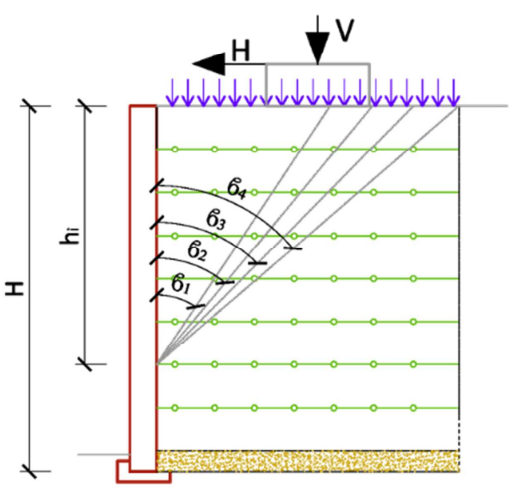

b)

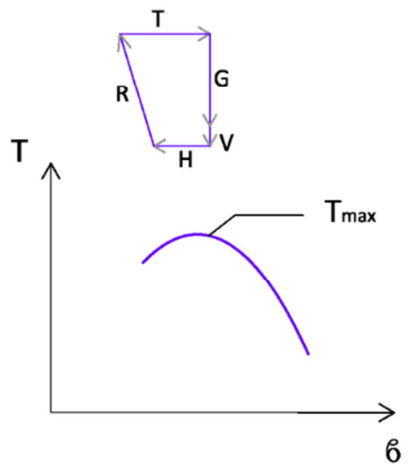

c)

Fig. 1: Tieback Wedge Method principle, [3, 4].

The horizontal force $T_{F i}$ acting in the structure as a result of the vertical load from the effects of self-weight of backfill and surcharge of terrain $q$, (Fig. 1). Forces from equations (1) and (2) are calculated by following equations $(3-6)$ :

$T_{F i}=K_{a} \cdot \sigma_{z i} \cdot v_{i}$,

$T_{v i}=K_{a 1} \cdot v_{i} \frac{\gamma_{F} \cdot V}{d_{i}}$,

where: $K_{a}$ - is coefficient of active pressure, $K_{a 1}$ - coefficient at active zone with soil 1 ,

$\sigma_{z i}$ - vertical pressure at level of reinforcement,

$v_{i}$ - vertical distance between reinforcement,

$d_{i}$ - distance from center of surface load of width $b$ to back side of contacting wall element, $d_{i}=\left(h_{i}+b\right)$; if $h_{i} \leq(2 \mathrm{D}-b)$ and $d_{i}=\left(h_{i}+b\right) / 2+b$; if $h_{i}>(2 \mathrm{D}-b)$,

$V$ - vertical force acting on surface block,

$\gamma_{F}-$ partial factor of safety. 
$T_{H i}=2 \cdot v_{i} \cdot \gamma_{F} \cdot H \cdot Q \cdot\left(1-h_{i} \cdot Q\right)$,

$T_{c i}=2 v_{i} \frac{c^{\prime}}{\gamma^{\prime}} \sqrt{K_{p 1}}$,

where: $Q \quad$ - is obtained through formula $Q=\tan \left(45-\varphi^{\prime} / 2\right) /(\mathrm{D}+b / 2)$,

$K_{p 1}$ - passive pressure coefficient in block of soil 1.

\subsubsection{Evaluation of breakage of one layer of reinforcement}

Reinforcing element can be geogrid of certain tensile strength, this must be checked step by step in every position of height of MSE wall, and therefore design tensile strength in every place must be higher than acting tensile force

$$
\frac{T_{d}}{\gamma_{n}} \geq T_{i}
$$

Design tensile strength can be derived from ultimate tensile strength (short-term) $T_{u l t}$ or from extrapolated long-term tensile strength $T_{k e}$,

$$
T_{d}=\frac{T_{u l t}}{\left(\gamma_{m 1} \cdot \gamma_{m 2} \cdot \gamma_{m 3} \cdot \gamma_{m 4} \cdot \gamma_{n}\right)} \text { resp. } T_{d}=\frac{T_{k e}}{\left(\gamma_{m 11} \cdot \gamma_{m 2} \cdot \gamma_{m 3} \cdot \gamma_{m 4} \cdot \gamma_{n}\right)} \text {, }
$$

where partial factor coefficients $\gamma_{m i}$ are taking into account material properties, environment of structure, installation technology [2], $\gamma_{n}$ is factor of safety according to importance of structure, $[5,6]$.

\subsubsection{Assessment of pull-out failure of reinforcement}

Condition that must ensure pull-out resistance stability of each reinforcement in MSE wall structure is expressed by formula, $[3,8,9]$ :

$$
P_{i} \geq \frac{T_{i}}{\frac{\mu_{g s} \cdot L_{k i}\left(\gamma_{F} \cdot \gamma_{1} \cdot h_{i}+\gamma_{F} \cdot q\right)}{\gamma_{p} \cdot \gamma_{n}}+\frac{\alpha_{b c}^{\prime} \cdot c^{\prime} \cdot L_{k i}}{\gamma_{c} \cdot \gamma_{P} \cdot \gamma_{n}}}
$$

where: $P_{i} \quad$-interacting upper and bottom length of reinforcement for $1 \mathrm{~m}$ of wall structure,

$L_{k i} \quad$ - is anchored length of geogrid (Fig. 1a),

$\mu_{g s}-$ surface friction coefficient of geogrid and fill material $\mu_{g s}=\alpha^{\prime} \cdot \tan \left(\varphi^{\prime}\right) / \gamma_{\varphi^{\prime}}$,

$\alpha^{\prime} \quad$-interaction ratio from pull-out test (also known as $c_{i}$ ),

$\alpha_{b c}$ ' - scale factor for cohesion interpretation on anchored length,

$\gamma_{F}$ - partial factor of safety,

$\gamma_{p}$ - partial factor for pull-out resistance,

$\gamma_{n}$ - factor of safety according to importance of structure.

\subsubsection{Wedge failure check of reinforced wall}

Wedge failure analysis of MSE wall structure assumes that each wedge acts as a solid unit. Slip surface of wedge is determined by the angle $\beta$ (Fig. 1a). The potential shear surface according to theory of Mohr-Coulomb is defined by angle $\beta=\left(45^{\circ}-\varphi^{\prime}{ }_{1} / 2\right)$, for this case the wall is loaded by uniform continuous load $q$. In general, the slope which is the most unfavourable cannot be determined, so it is necessary to consider more individual wedges for determination of maximal acting force $T$. Slip surfaces are drawn to pass the contact surface load $q$ (Fig. 1b). Maximal required strength is then evaluated from chart for each wedge analysed with different inclination angle $\beta$ (Fig. 1c). Stability is guaranteed when every wedge mechanism is stabilized by total design tensile strength of 
reinforcement, or resistance force against pull-out. The lesser value for each layer should be used in the summation:

$$
\sum_{i=1}^{m}\left[\frac{T_{d i}}{\gamma_{n}}\right] \geq T \text { or } \sum_{i=1}^{m}\left[\frac{P_{i} \cdot L_{k i}}{\gamma_{p} \cdot \gamma_{n}}\left(\mu_{g s} \cdot \gamma_{F} \cdot \gamma_{1}^{\prime} \cdot h_{i}+\mu_{g s} \cdot \gamma_{F} \cdot q+\frac{\alpha_{b c}^{\prime} c^{\prime}}{\gamma_{c^{\prime}}}\right)\right] \geq T \text {. }
$$

\subsection{Coherent gravity method}

This method supposes splitting a reinforcing block of soil into two zones - active and passive, defined by curve of acting maximal tensile stress, Fig. 2a, 2b. Distribution of maximal stress in reinforced block of soil depends on tensile stiffness of used reinforcement. For steel strip

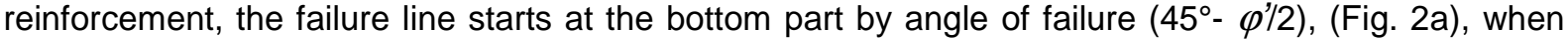
extensible reinforcement is used, failure curve is supposed (Fig. 2b). In this method, the coefficient of earth pressure $K_{i}$ is in relation with height of structure (Fig. 2c) and can be calculated according to depth $z$, measured from the top of reinforced wall:

$$
\begin{array}{ll}
K_{i}=K_{0} \cdot\left(1-\frac{z}{z_{0}}\right)+K_{a} \frac{z}{z_{0}} & \text { if } z \leq z_{0}=6 m, \\
K_{i}=K_{a} & \text { if } z>z_{0} .
\end{array}
$$

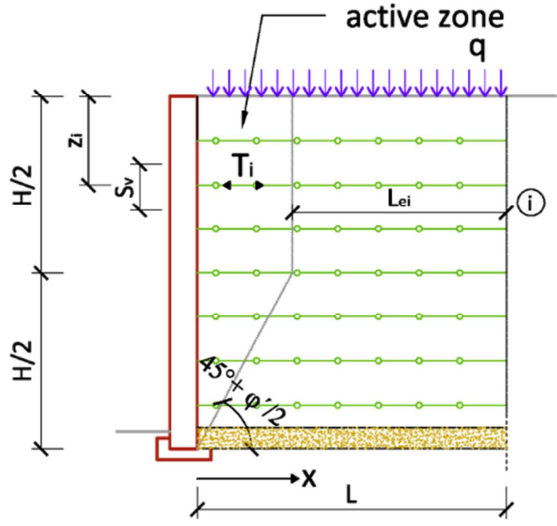

a)

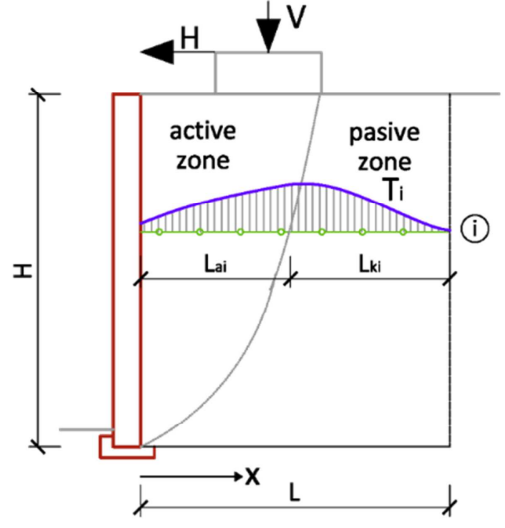

b)

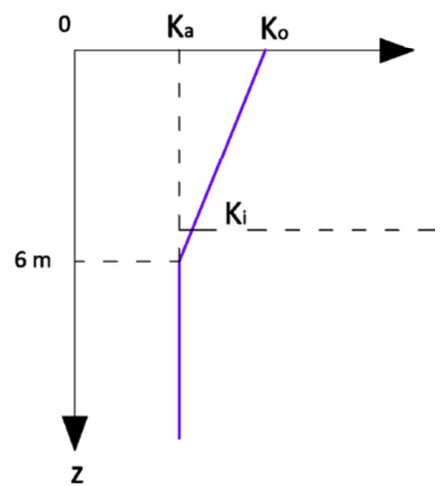

c)

Fig. 2: Principle of calculation by Coherent Gravity method, [4, 8, 9].

\subsubsection{Evaluation of breakage of each layer}

Similarly, like previous method using, breakage of each geogrid is performed by simple equation (7).

\subsubsection{Assessment of pull-out resistance of one layer of reinforcement}

$T_{i} \leq \frac{2 B \mu_{g s}}{\gamma_{v} \cdot \gamma_{n}} \int_{L-L_{a i}}^{L} \gamma_{F} \cdot \sigma_{z}(x) d x$,

where: $B-$ is width of reinforcement,

$\mu_{g s}-$ is surface friction coefficient of geogrid and fill material,

$\sigma_{z(x)}$ - vertical stress at depth $z$, through $x$ direction,

$\gamma_{v}, \gamma_{n}-$ partial factor sets, [9].

Two other known methods are also used for internal stability check, first one is Simplified method and second one is Structural Stiffness method [4, 6], which were not used in our comparison. 


\section{FEM model and comparison of results}

Nowadays, many of the analytical design software are ready to use, which are personalised to manufactures of geosynthetics and limitations must be known. FEM modelling has become increasingly popular, as it is a general tool for evaluating all kinds of limit states of structures. Simple model of MSE wall structure has been created to demonstrate variability of calculations and advantages such as construction phase evaluation, calculation of deformation of structure, dynamic loading, consolidation calculation on soft subsoil, etc.

The parametric FEM model of MSE wall structure has been created with the following parameters:

- height of wall $8 \mathrm{~m}$,

- uniform reinforcement length of $8 \mathrm{~m}$ with regular vertical distance of $0.80 \mathrm{~m}$,

- concrete face elements,

- reinforcement by a) standard geogrid RE520 with tensile stiffness of $1000 \mathrm{kN} / \mathrm{m}$; b) high tensile strips 2D/40 of stiffness $1141 \mathrm{kN} / \mathrm{m}$, and c) metal strip 504/HA of elastic tensile stiffness $80000 \mathrm{kN} / \mathrm{m}$,

- high tensile strips b) and metal strips c) were fixed in embankment by anchor fixation, geogrid model a) had inactive fixation in order to simulate real installation condition,

- Mohr-Coulomb material model has been used for fill material, and linear elastic for reinforcement elements, geometry was defined by 15 -nodes FEM elements,

- crushed stone as filling material, with angle of friction $\varphi^{\prime}=36^{\circ}$, dilatancy angle $\lambda=6^{\circ}$ and cohesion $7 \mathrm{kPa}$ and interface coefficient $R_{\text {int }}=0.9$,

- foundation conditions of MSE wall structure are average in construction areas, foundation soil is classified as clayey gravel G5 $=\mathrm{GC}$ with $\gamma=19,2 \mathrm{kN} / \mathrm{m}^{3} ; \varphi^{\prime}=28^{\circ} ; c^{\prime}=15 \mathrm{kPa}$ and has oedometric modulus $E_{\text {oed }}=110 \mathrm{MPa}$.

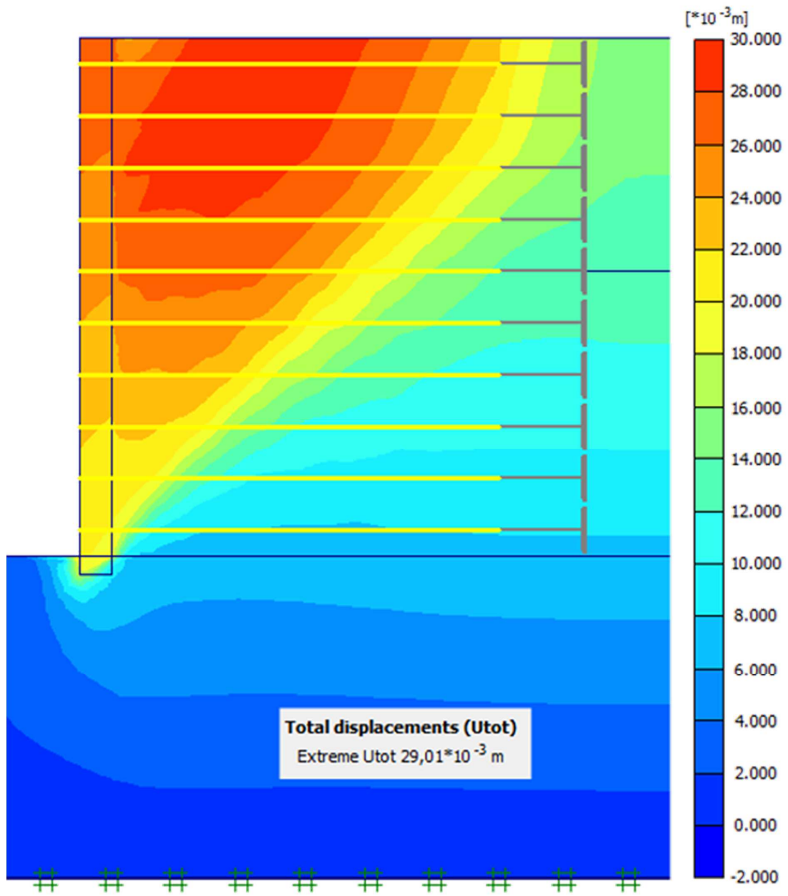

a)

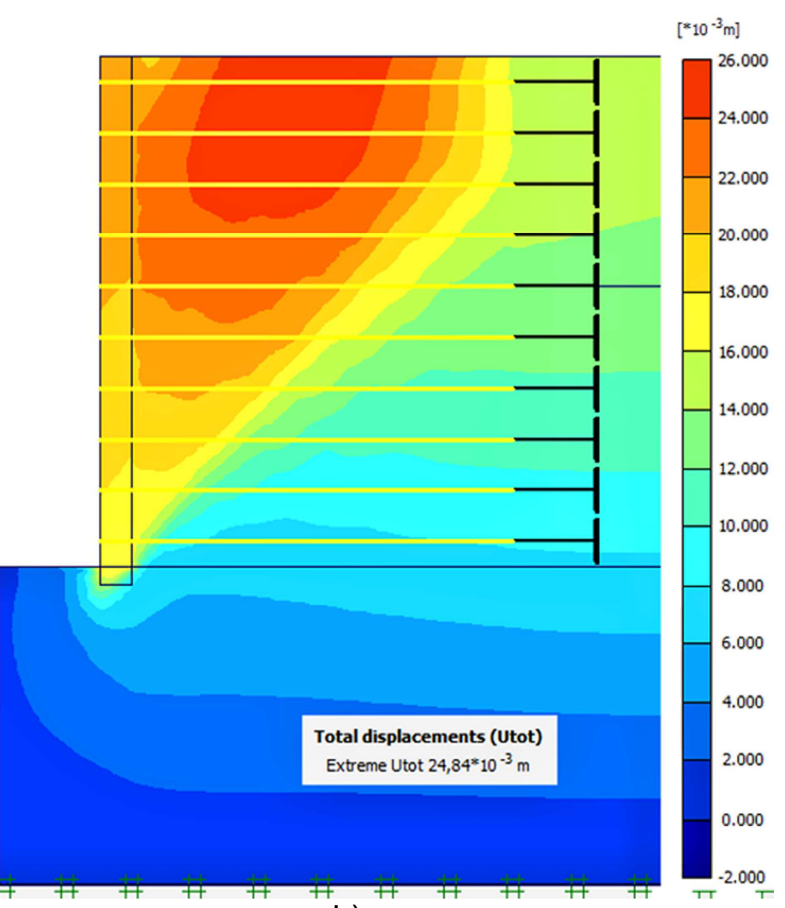

b) 


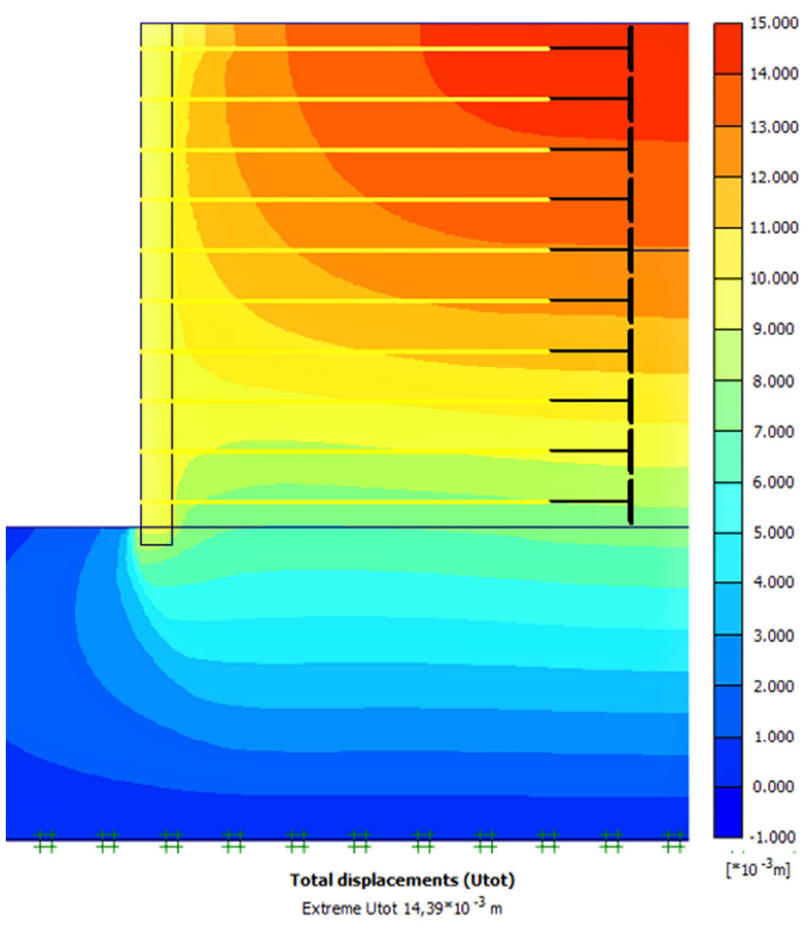

c)

Fig. 3: Results of numerical analysis - total displacement of MSE wall reinforced by: a) geogrid - max. displacements $29 \mathrm{~mm}$, b) high tensile geosynthetic strips - max. $25 \mathrm{~mm}, \mathrm{c}$ ) metal strips - max. $14 \mathrm{~mm}$.

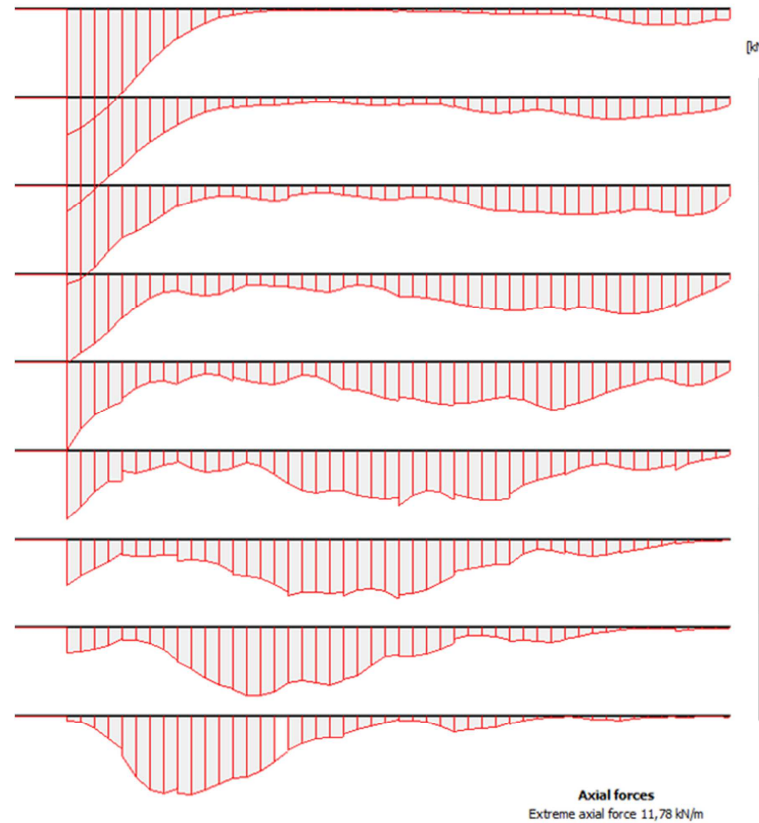

a)

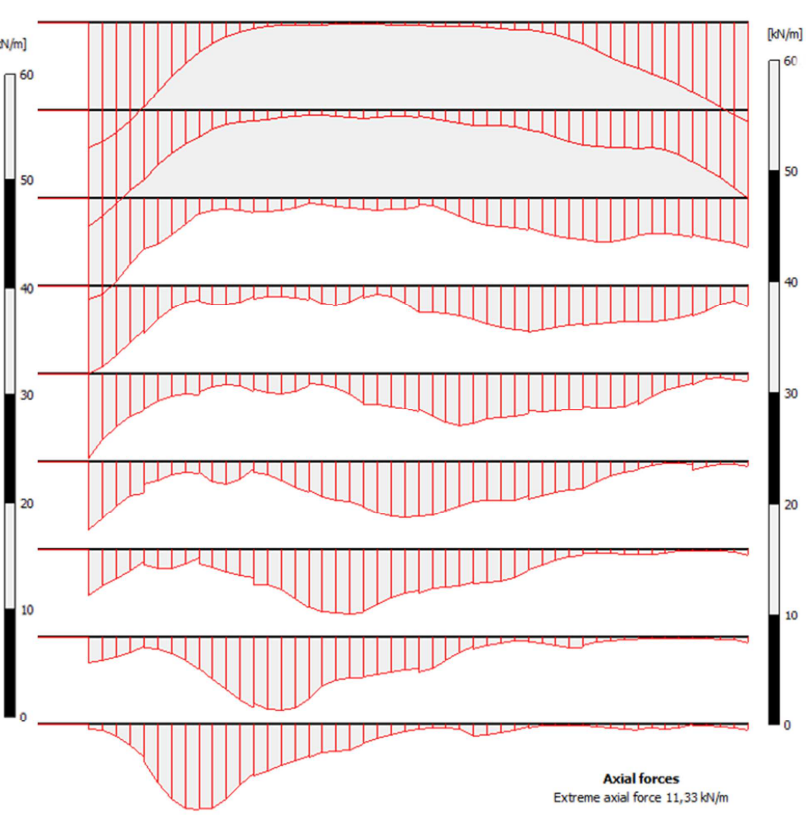

b) 


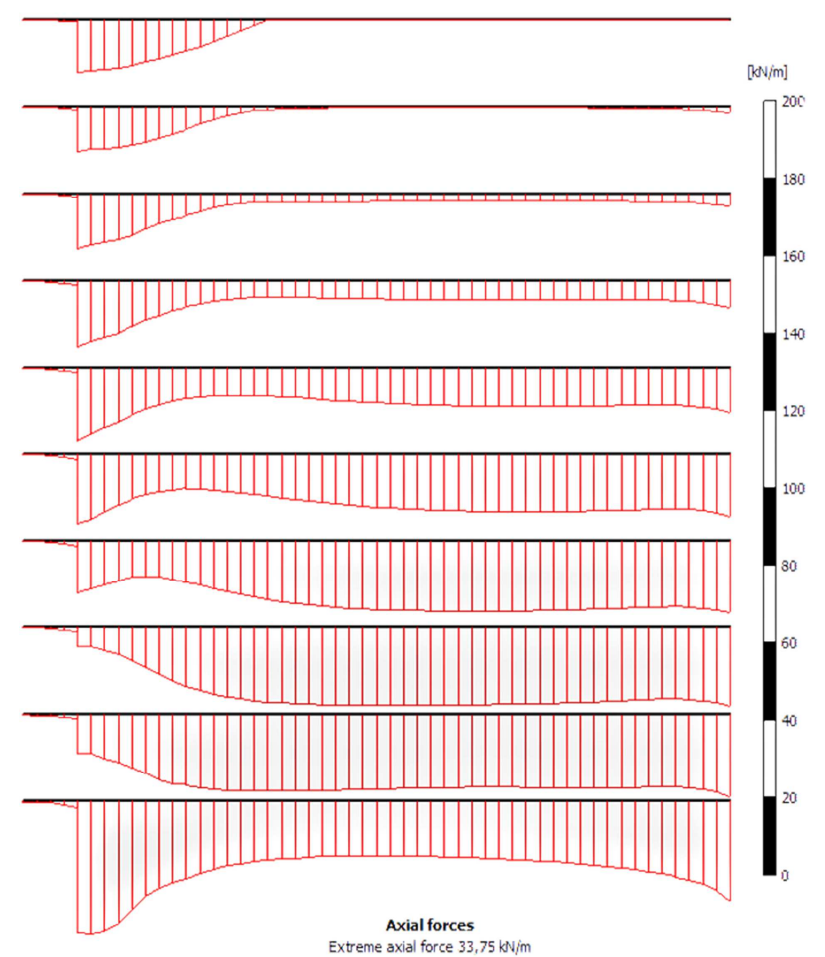

c)

Fig. 4: Results of numerical analysis - horizontal displacement of wall reinforced by: a) geogrid, b) high tensile geosynthetic strips, c) metal strips.

Maximal tensile forces are indicated in metal strips $33.7 \mathrm{kN} / \mathrm{m}$ (Fig. 4c), which have also highest stiffness; maximal deformations are indicated at GGR reinforced wall $29 \mathrm{~mm}$, (Fig. 3a). Horizontal deformations are at case a) $22 \mathrm{~mm}$, b) $16.5 \mathrm{~mm}$, and c) $2 \mathrm{~mm}$. Interesting is behaviour of strips in two last layers, where tensile forces are acting closed to fixation of face. This can be explained by higher settlement of wall in central zone comparing with settlement in face zone. In this case, total displacements are playing role for indication of tensile forces in metal strips reinforcement.

It must be mentioned, that analytical calculations are not able to take into account deformations of subsoil. When favourable foundation soil is present or wall face part is supported by piles, difference between results of analytical and numerical analyses are higher. Therefore, standard conditions of MSE wall structure were supposed.

According to shape of deformation at cases a) and b) of Fig. 3 and Fig. 4 similar stiffness can produce similar deformation of wall. Higher stiffness of metal strip reinforcement confirmed lower deformation of wall by numerical analysis.

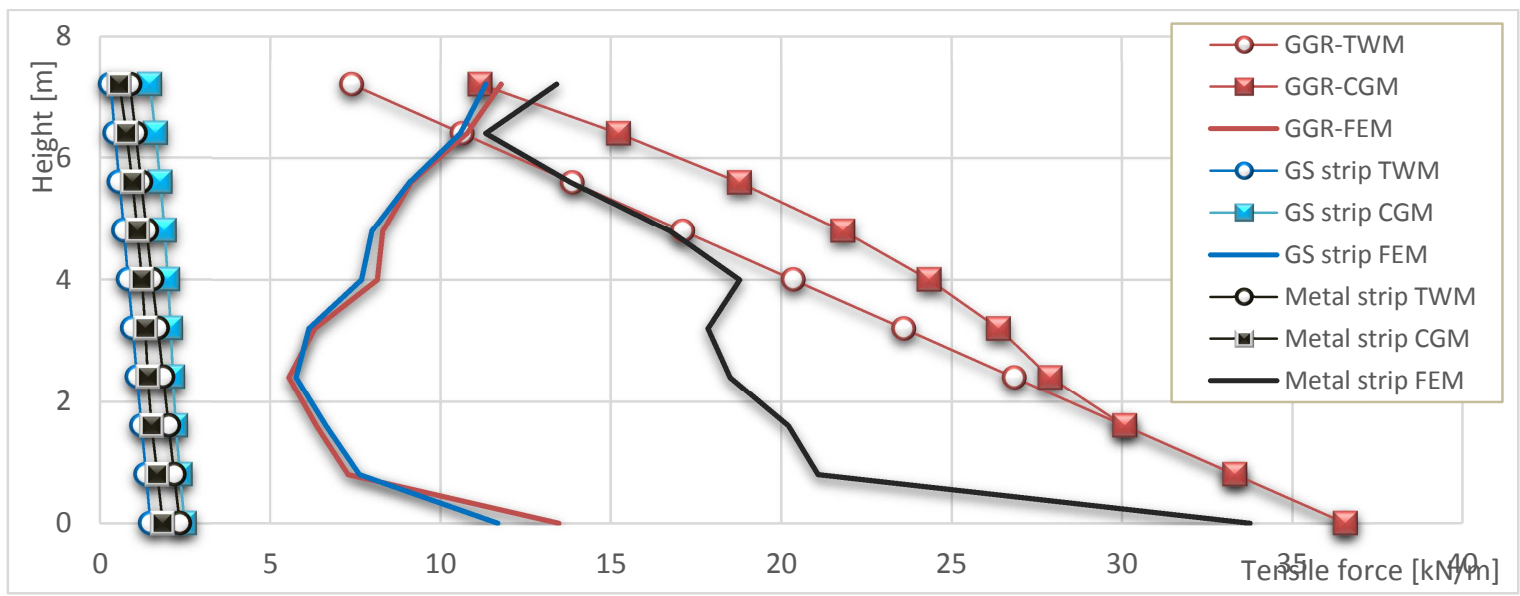

Fig. 5: Comparison of calculated tensile forces by Tie-back Wedge Method (TWM) and Coherent Gravity Method (CGM) and by numerical model (FEM) of MSE wall reinforced by: a) geogrid (GGR), b) high tensile geosynthetic strips (GS strip), and c) metal strips. 
The difference between results of FEM analysis and analytical methods are significant (Fig. 5). Analytical results have linear tendency, which were not confirmed by FEM analyses, where in level of $1-2 \mathrm{~m}$ of wall height can be seen relaxation and lower values of tensile forces. It is difficult to judge precision of analytical methods when real measurements were not done.

\section{Conclusions}

Design methods of MSE wall structure are quite well developed. In this article has been demonstrated that stiffness of reinforcement has significant influence on face deformation of structure, $[10,11]$. This problematic issue is known and construction technology recommends building wall with inclination to backfill. Analytical methods should be sufficiently precise to evaluate internal stability and design of tensile strength of reinforcement. FEM models are more suitable for evaluation of limit deformations of a structure and also global stability and consolidation settlement. It can be mentioned that interaction between reinforcement and fill material should be simulated by shear interfaces along reinforcing element, $[4,10]$. Practical experiences made favourable direct input $R_{\text {int }}$ coefficient into the layer of interacting fill. When forces derived from different calculation approaches are compared, it can be found good correlation between analytical methods, but FEM results might be realistic $[12,13]$.

\section{References}

[1] BERG, R. R. - CHRISTOPHER, B. R. - SAMTANI, N. C.: Design and Construction of Mechanically Stabilized Earth Walls and Reinforced Soil Slopes - Volume I. Publication No. FHWA-NHI-10-024, FHWA GEC 011 - Volume I, 11/2009.

[2] DECKÝ, M. - DRUSA, M. - PEPUCHA, L'. - ZGÚTOVÁ, K.: Earth Structures of Transport Constructions. Harlow: Essex: Pearson, pp.180, 2013, ISBN 978-1-78399-925-5.

[3] BS 8006-1:2010: Code of Practice for Strengthened/Reinforced Soils and Other Fills.

[4] VLČEK J.: Some issues of design structures reinforced by geosynthetics. PhD thesis 28250320123001 , University of Žilina, 2012.

[5] DRUSA, M. et al.: Verification of the results of the geotechnical monitoring using finite element method. In: International Multidisciplinary Scientific GeoConference Surveying Geology and Mining Ecology Management, SGEM, 2013, p. 533 - 540.

[6] http://www.danskgeotekniskforening.dk, The Design of Reinforced Earth Walls, Danish Geotechnical Society Seminar on Reinforced Earth - 28/11/2013, online (09/2016).

[7] DOBIE, M.: Internal stability of reinforced soil structures using a two-part wedge method. Indonesian Geotechnical Conference and Annual Scientific Meeting, Jakarta 2011.

[8] ALLEN, $T$ et al.: Development of the Simplified Method for Internal Stability Design of Mechanically Stabilized Earth Walls. Washington, D.C.: FHWA, 2001, p.108.

[9] MORACI, N. - GIOFFRE D.: A simple method to evaluate the pullout resistance of extruded geogrids In: Geotextiles and Geomembranes. ISSN 0266-1144, 24 (2006), p. 116 - 128.

[10]DRUSA, M. et al.: Design and control of earth structures on transport constructions. EDIS, 2013. ISBN 978-80-554-0823-1, (in Slovak).

[11]DRUSA M. - VLČEK J.: Importance of Results Obtained from Geotechnical Monitoring for Evaluation of Reinforced Soil Structure - Case Study. In: Journal of Applied Engineering Sciences. De Gruyter Open, ISSN 2247-3769, Vol 6., Issue 1/2016.

[12]MUŽíK, J.: A 2-D meshless model for soil subsurface settlement. In: Applied Mechanics and Materials. Trans Tech Publications, ISSN1660-9336, 2014, p. 209 - 214.

[13] KERRY ROWE, R.: Geotechnical and Geoenvironmental Engineering Handbook. Edition, 2001, ISBN-13: 978-1461356998. 